\title{
Should we kiss?
}

\section{Marin Vučković*, -Sandra Makarović, OZorin Makarović, Damir Kirner}

University Hospital Centre Osijek, Osijek, Croatia
RECEIVED:

February 19, 2020

ACCEPTED:

February 22, 2020

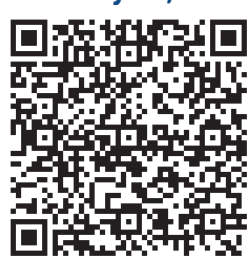

KEYWORDS: coronary artery bifurcation, provisional stenting, kissing balloons.

CITATION: Cardiol Croat. 2020;15(3-4):47. | https://doi.org/10.15836/ccar2020.47

*ADDRESS FOR CORRESPONDENCE: Marin Vučković, KBC Osijek, J. Huttlera 4, HR-31000 0sijek, Croatia. / Phone: + 385-98-278-937 / E-mail: marin.vuckovic@gmail.com

ORCID: Marin Vučković, https://orcid.org/0000-0003-1010-181X·Sandra Makarović, https://orcid.org/0000-0002-7487-1189 Zorin Makarović, https://orcid.org/0000-0002-6689-3177• Damir Kirner, https://orcid.org/0000-0002-6001-3378

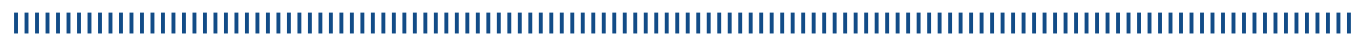

Atherosclerotic disease predominantly occurs in the position of the biggest blood turbulations. Pathophysiologicaly this position is prone to shear stress. In interventional cardiology this position is called coronary bifurcation. Bifurcation stenting depends on distribution of atherosclerotic burden and anatomical structure of main and side branches. The problem lies in wright conformation of delivered stents and wright anatomical structure that should mimic natural blood flow. Because of this physical law debate is on how to adequately form positioned stents through postdilatation. One common way is doing kissing balloons. We will show the importance of these techniques through medical literature data $^{1,2}$, that were published in last 5 years, and try to propose recommendation for kissing balloons in one stent, and two stents techniques. We will show several examples of one and two stent techniques and our solutions. In conclusion, based on literature review and our practice, we think that kissing balloon could be optional in provisional stenting, but desirable, not mandatory, in two stents techniques.

LITERATURE IIIIIIIIIIIIIIIIIIIIIIIIIIIIIIIIIIIIIIIIIIIIIIIIIIIIIIIIIIIIIIIIIIIIIIIIIIIIIIIIIIIIIIIIIIIIIIIIIIIIIIII

1. Chen SL, Zhang JJ, Han Y, Kan J, Chen L, Qiu C, et al. Double Kissing Crush Versus Provisional Stenting for Left Main Distal Bifurcation Lesions: DKCRUSH-V Randomized Trial. J Am Coll Cardiol. 2017 Nov 28;70(21):2605-2617. https://doi.org/10.1016/j.jacc.2017.09.1066

2. Ahn JM, Lee PH, Park DW, Kang SJ, Lee SW, Kim YH, et al. Benefit of Final Kissing Balloon Inflation Mandatory After Simple Crossover Stenting for Left Main Bifurcation Narrowing. Am J Cardiol. 2017 Feb 15;119(4):528-534. https://doi.org/10.1016/j.amjcard.2016.11.002 